ISSN 0103-5150

Fisioter. Mov., Curitiba, v. 30, n. 3, p. 639-649, Jul./Sep. 2017

Licenciado sob uma Licença Creative Commons

DOI: http://dx.doi.org/10.1590/1980-5918.030.003.AR04

(c)

\title{
Isotonic saline nasal irrigation in clinical practice: a literature review
}

\author{
O uso da ducha nasal com solução salina na \\ prática clínica: uma revisão da literatura
}

\author{
Sabrina Costa Lima ${ }^{[a]}$, Ana Carolina Campos Ferreira ${ }^{[b]}$, Tereza Cristina da Silva Brant ${ }^{[b] *}$ \\ [a] Faculdade de Ciências Médicas de Minas Gerais (FCM-MG), Belo Horizonte, MG, Brazil \\ [b] [b] Universidade Federal de Minas Gerais (UFMG), Belo Horizonte, MG, Brazil
}

\begin{abstract}
Introduction: Nasal instillation of saline solution has been used as part of the treatment of patients with upper respiratory tract diseases. Despite its use for a number of years, factors such as the amount of saline solution to be used, degree of salinity, method and frequency of application have yet to be fully explained. Objective: Review the reported outcomes of saline nasal irrigation in adults with allergic rhinitis, acute or chronic sinusitis and after functional endoscopic sinus surgery (FESS), and provide evidence to assist physiotherapists in decision making in clinical practice. Methods: A search was conducted of the Pubmed and Cochrane Library databases between 2007 and 2014. A combination of the following descriptors was used as a search strategy: nasal irrigation, nasal lavage, rhinitis, sinusitis, saline, saline solution. Results: Eight clinical trials were included, analyzed according to participant diagnosis. Conclusion: The evidence found was heterogeneous, but contributed to elucidating uncertainties regarding the use of nasal lavage in the clinical practice of physical therapy, such as the protocols used.
\end{abstract}

Keywords: Isotonic Solutions. Rhinitis. Sinusitis. Mucociliary Transport.

* SC: Graduate Student, e-mail: sabrinalima.fst@gmail.com ACC: Specialist, e-mail: fisioterapia.anacarolina@gmail.com

TCS: PhD, e-mail: terezabrantufmg@gmail.com 
Resumo

Introdução: A instilação nasal de solução salina tem sido utilizada como parte do tratamento de pacientes com doenças do trato respiratório superior. Apesar de ser utilizada há vários anos, fatores como: quantidade da solução a ser instilada, grau de salinidade, modo e frequência de aplicação ainda não foram totalmente elucidados. Objetivo: Revisar os desfechos evidenciados no uso da irrigação nasal salina em adultos com rinite alérgica, sinusite aguda ou crônica e em pós-operatório de cirurgia endoscópica dos seios da face (CES) além de fornecer evidências para a tomada de decisões do fisioterapeuta na sua prática clínica. Métodos: Realizou-se uma busca nas bases de dados Pubmed e Cochrane Library no período compreendido entre 2007 e 2014. Foi utilizada como estratégia a combinação dos seguintes descritores: nasal irrigation, nasal lavage, rhinits, sinusitis, saline, saline solution. Resultados: Foram incluídos oito ensaios clínicos, analisados de acordo com o diagnóstico dos participantes. Conclusão: As evidências encontradas mostraram-se heterogêneas, mas contribuíram para elucidar alguns pontos obscuros na prática clínica da fisioterapia com relação ao uso da ducha nasal, como por exemplo, os protocolos utilizados.

Palavras-chave: Soluções Isotônicas. Rinite. Sinusite. Transporte Mucociliar.

\section{Introduction}

The main symptom of upper respiratory tract conditions such as allergic rhinitis and acute and chronic rhinosinusitis is nasal congestion, which in addition to causing discomfort, contributes significantly to absenteeism from work or school (1). These conditions are frequent sources of morbidity, prompting an increase in healthcare costs and loss of productivity $(2,3)$. In the United States, it is estimated that $14 \%$ of the population suffers from rhinosinusitis, while statistics on the incidence and prevalence of this disease are not available for Brazil (4).

Functional endoscopic sinus surgery (FESS) is indicated in cases of chronic sinusitis that are unresponsive to conventional clinical treatment (5). The postoperative period interferes in the transport of particles towards the pharynx and delays mucociliary clearance (MCC) (6), favoring the accumulation of secretions in the upper respiratory tract (URT) and compromising the lower airways.

Typical treatments include the use of decongestants, mucolytics, antihistamines, corticosteroids and antibiotics (7). Saline solution is recommended (8) in conjunction with medication to relieve symptoms, particularly in patients with allergic rhinitis (9-11), sinus conditions $(12,13)$ and after FESS $(5,14,15)$.

According to the literature, the mechanism of action of nasal irrigation remains unknown (16). Some hypotheses attribute the improvement of symptoms to different physiological effects, including greater displacement of mucus towards the nasopharynx as a direct physical effect $(13,17)$ through the softening and dislodging of mucus crusts due to nasal lavage, as well as the reduction of inflammatory mediators $(13,17,18)$ and increased ciliary beat frequency $(17)$.

Harvey et al. (19) classified saline solution delivery systems in nasal irrigation into high positive pressure and low negative pressure. The former can be used in high volumes via a syringe, squeeze bottles, pressurized spray and devices that produce a pulsating stream, or low volumes in the form of a simple spray, metered-dose spray and atomizers. Low negative pressure can be generated in high volumes using neti pots and nasal inhalers or in low volumes via catheters, eye droppers, nasal nebulizers and by rapid and strong sniffing of a nasal solution from the palm of the hand with both nostrils (20).

Mechanical clearance through a saline solution requires the use of high volumes under positive pressure (21) in order to ensure that crusts adhered to the nasal cavity are removed. Saline instillation under high pressure generates the shear force needed to alter gas-liquid interaction, favoring the removal of viscous mucus adhered to the walls of the airways, inflammatory cells, pollutants and bacteria $(12,16,21)$.

Although nasal irrigation has been used for several years, factors such as the amount of saline solution to be used, degree of salinity, method and frequency of application, as well as the parameters to be 
assessed, have yet to be scientifically elucidated. With respect to the volume instilled into the nasal cavity, there is no consensus on the amount to be used or the best position to be adopted by patients during penetration of the saline solution into the nose and paranasal sinuses (21).

Given the wide use of saline nasal irrigation in medical and physiotherapy clinical practice, lack of physiotherapy research on the issue in the databases searched, the dearth of studies reporting standardization of the technique and the impact of URT obstruction in terms of compromising the intrathoracic pathways (due to post-nasal drip) and lungs, the present study aimed to review the use of saline nasal irrigation in adults with allergic rhinitis, acute or chronic sinusitis and after functional endoscopic sinus surgery (FESS), and provide a summary of this evidence to assist physiotherapists in applying nasal lavage in clinical practice.

\section{Methods}

This is a narrative literature review involving a search of the Medical Literature Analysis and Retrieval System Online (MEDLINE/Pubmed) and Cochrane Library databases from May 2014 to November 2015. Papers included were observational studies, and clinical and randomized trials that investigated the use of saline nasal irrigation as part of the non-pharmacological treatment of patients with allergic rhinitis, sinusitis and following FESS.

With a view to increasing search sensitivity and accuracy, the strategy used was adapted for each database, using the Boolean operator and along with a combination of the following descriptors related to nasal irrigation: nasal irrigation, nasal lavage, rhinitis, sinusitis, saline, and saline solution.

The following inclusion criteria were established: containing the abovementioned terms in the title or abstract; clearly explaining the protocol used for saline nasal irrigation in the methodology and being published in English or Portuguese from 2007 to 2014.
Participants had to be adults (from 18 years old), in the acute (symptoms lasting up to four weeks) or chronic phase (persistent signs and symptoms for more than twelve weeks) of the disease.

Study selection involved three different stages. The first consisted of reading the titles of all the studies resulting from the search and excluding those that clearly did not meet the previously established inclusion criteria. In the second stage, a critical reading of the abstracts of studies selected in the previous phase was performed to determine whether they met the inclusion criteria, and in the final (third) stage the previously selected articles were read in full.

All the stages were conducted by two independent physiotherapists, one of whom had experience using saline nasal irrigation. In the event of disagreement, a third experienced evaluator was consulted.

The clinical trials included were rated using the PEDro scale, available on the Physiotherapy Evidence Database (22).

\section{Results}

The initial search of MEDLINE using the term nasal irrigation found 2155 studies, 502 of which were excluded for analyzing cadavers, guinea pigs or the instillation of substances other than saline, leaving 1653 articles. Inclusion of the filter adults left 1324 studies. Selection of the study design and publication period reduced the number of studies to 135. Application of the filter diseases resulted in the inclusion of six studies from this database.

On the Cochrane Library database, 174 articles were initially identified, falling to 30 after inclusion of the study population. Including the type of disease produced 10 scientific articles and selecting the study design resulted in the final inclusion of two publications from this database. The search strategies used for each of the databases are shown in Figure 1. 


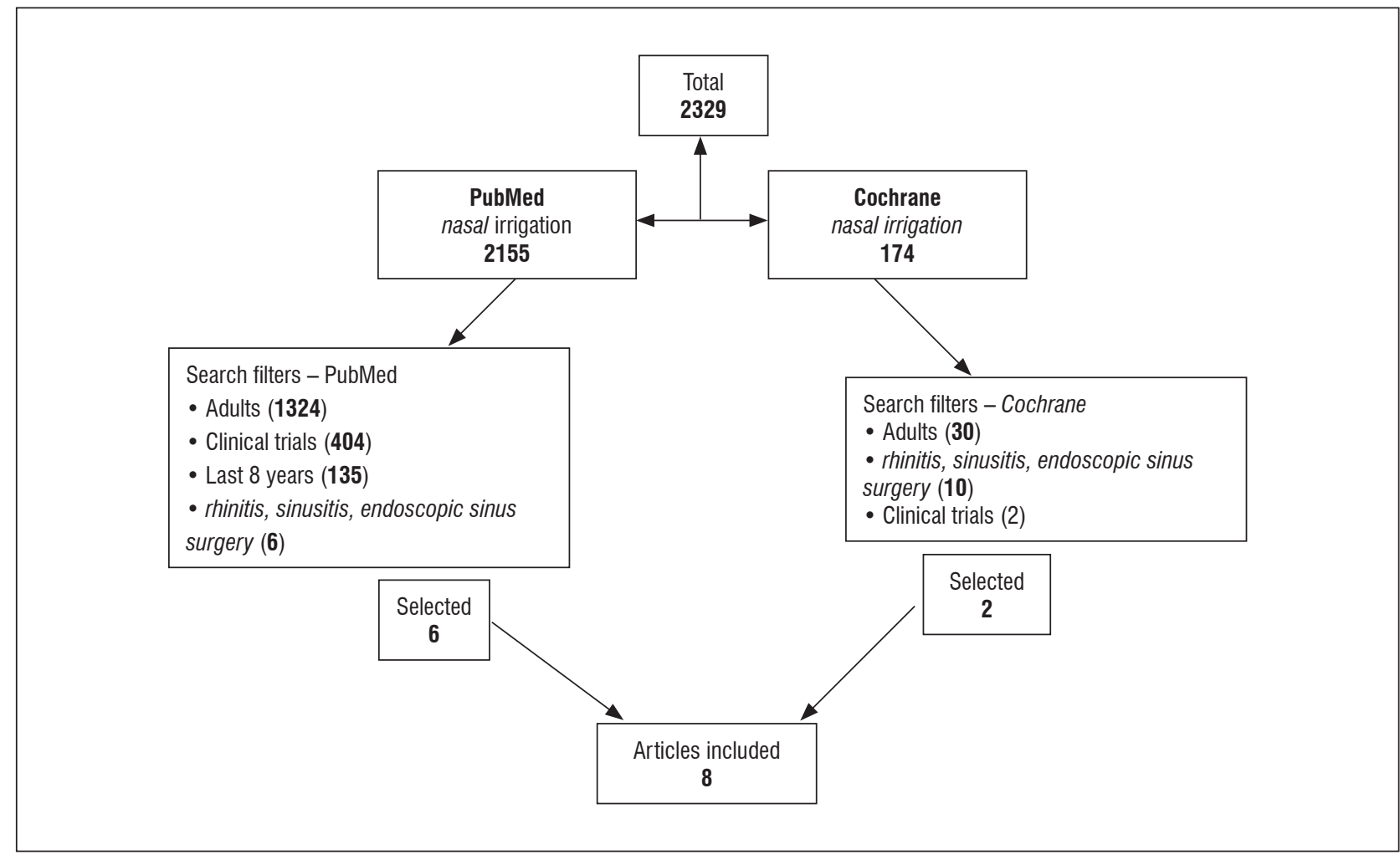

Figure 1 - Flow chart depicting the search and article selection.

A total of eight studies, selected from the two databases and analyzed according to the diseases investigated, were included in this literature review, as follows: rhinitis $(20,23)$ sinusitis $(6,12)$ and FESS $(5,14,15,24)$. The characteristics of the studies are summarized in Table 1.
In short, the protocols analyzed exhibited heterogeneity. Although most of the studies were randomized clinical trials $(5,6,12,14,15,23)$, none obtained the maximum score on the PEDro scale (22), with scores ranging between five and seven points. None of the studies used a control group and four $(5,12$, 14,20 ) associated nasal irrigation with medication. 


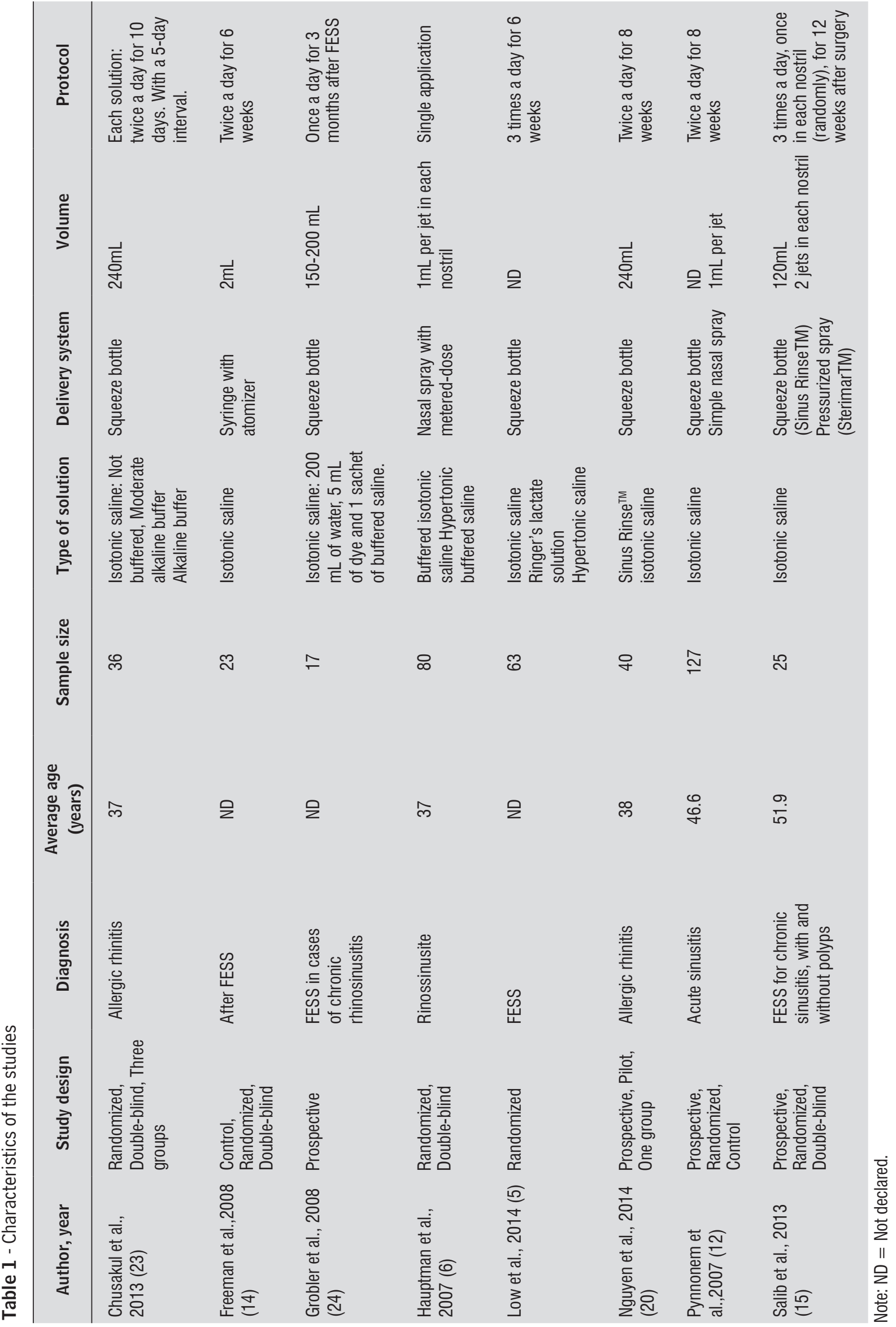




\section{Rhinitis}

Nguyen et al. (20) used Sinus Rinse ${ }^{\mathrm{TM}}$ isotonic saline in combination with an intranasal corticoid twice a day for eight weeks, with assessments conducted at baseline and in the $4^{\text {th }}$ and $8^{\text {th }}$ weeks, in 40 patients with allergic rhinitis. Nasal irrigation associated with corticoids reduced scores on the Mini Rhinoconjunctivitis Quality of Life Questionnaire (mRQLQ), with scores of $36.7 \pm 20.48$ (baseline), 14.9 $\pm 11.03\left(4^{\text {th }}\right.$ week) and $10.10 \pm 10.65\left(8^{\text {th }}\right.$ week $)(\mathrm{p}<$ 0.001). However, no changes were observed in the assessment of peak nasal inspiratory flow. An intranasal corticoid was used in association with saline irrigation since, like antihistamines, this type of drug is often adopted to alleviate symptoms in those with allergic rhinitis (20).

Chusakul et al. (23) studied three types of isotonic saline solutions: non-buffered $(\mathrm{pH}=6.2-6.4)$, moderately alkaline buffer $(\mathrm{pH}=7.2-7.4)$ and alkaline buffer ( $\mathrm{pH}=8.2-8.4)$. The patients used the three solutions separately and in different orders, with a 5-day interval before using the new solution. A squeeze bottle was used to administer (instillation) $240 \mathrm{~mL}$ of saline solution twice a day for 10 days, with assessments conducted at baseline and after each solution was used. No significant differences were observed for any of the parameters analyzed ( $p>0.05)$. In relation to the type of saline used, participants showed a preference for the mildly alkaline solution $(p=0.02)$, while a reduction in symptoms such as sneezing was only observed when a saline solution with moderate alkalinity was applied $(\mathrm{p}=0.03)$.

\section{Sinusitis}

In the study by Pynnonen et al. (12), the authors evaluated the effects of saline nasal irrigation, administered using a squeeze bottle (Sinus Rinse ${ }^{\mathrm{TM}}, \mathrm{n}$ $=64$ ) and simple nasal spray (Deep Sea ${ }^{\mathrm{TM}}, \mathrm{n}=63$ ) twice a day, for eight weeks. The Sino-Nasal Outcome Test (20-SNOT-20 questionnaire) $(25,26)$ was used to analyze rhinosinusitis outcomes, indicating an improvement in the symptoms of the Deep SeaTM group, evident in the following scores: reduction of 4.4 points in the second week ( $p=0.02), 8.2$ points in the fourth $(\mathrm{p}<0.001)$, and 6.4 points in the eighth week $(p=0.002)$. The participants were advised to continue with their normal medication, including antihistamines, intranasal corticosteroids, decongestants and antibiotics.

In a cross-sectional study, Hauptman et al. (6) used the saccharin transit time (STT) test to assess the effects of saline irrigation on nasal patency and the functional status of MCC in 80 patients with rhinosinusitis. The reference value for STT in healthy adults is $\leq 12 \mathrm{~min}$ and $>0$. The subjects were divided into two groups according to the type of saline solution used (isotonic $n=40$, or hypertonic $n=40$ ), both buffered. The solutions were delivered using a metered-dose nasal spray (aerosol) that released $1 \mathrm{~mL}$ per jet. Each group was evaluated before and 10 minutes after saline irrigation. At the post-intervention assessment, a second-long reduction was observed for MCC in both groups (isotonic saline $702 \pm$ 21 , hypertonic saline $713 \pm 23, \mathrm{p}<0.0001$ ). However, instillation with hypertonic saline exhibited a greater decrease in STT.

\section{Before and after functional endoscopic sinus} surgery

In a randomized study, Freeman et al. (14) analyzed the effect of saline irrigation on reducing symptoms after FESS via endoscopic assess of the sinuses in 22 adults. Participants performed nasal irrigation three times a day for six weeks. During this period, nasal discharge improved ( $p=0.046)$, with no effect on mucosal edema ( $p=0.059$ ) or the presence of polyps ( $p=0.32$ ). After 3 months, the authors observed no differences in the formation of crusts, edema, the presence of polyps, adhesions or nasal discharge ( $p$ $>0.05$ ). During the study the subjects maintained their normal medication, including oral antibiotics and corticosteroids.

Low et al. (5) studied 63 patients submitted to FESS. The participants were randomly assigned to three groups according to the type of saline solution administered: isotonic saline, Ringer's lactate solution (saline solution formulated with a lower sodium content in relation to blood plasma and isotonic saline, in addition to potassium and calcium) and hypertonic saline $(2.7 \%)$. The solutions were used in the liquid state and administered with squeeze bottles; however, the authors did not report the volume used in each irrigation. Assessments were conducted in the first, third and sixth weeks after surgery. The SNOT-20 $(25,26)$ showed a significant 
decrease in postoperative scores in the first week for the Ringer's group (-14.67 points; 95\% CI -22.06 -7.27) when compared to isotonic ( -3.15 points; $95 \%$ CI -10.21 - 3.91) and hypertonic saline ( -4.24 points; $95 \%$ CI $-11.06-2,61$ ), with $\mathrm{p}<0.05$. This behavior continued to the sixth week, when all the groups showed improvement, but with Ringer's lactate obtaining superior results. A visual analog scale for nasal symptoms was also applied in association with the SNOT-20. It is important to underscore that analysis of the scale demonstrated similar group behavior to the SNOT-20, with an improvement in the Ringer's group (-6.72 points; 95\% CI -12.88 - -0.57) in relation to isotonic (2.86 points; $95 \% \mathrm{CI}-3.01-8.73)$ and hypertonic saline ( -0.81 points; $95 \% \mathrm{CI}-6.51-4.89$ ) with $\mathrm{p}<0.05$. No oral antibiotics or corticosteroids were administered during the study; however, intranasal corticosteroids were adopted by the participants between the second and third weeks.

The study by Salib et al. (15) evaluated 25 patients suffering from chronic rhinosinusitis, with and without polyps, submitted to FESS. The authors applied the SNOT-22 questionnaire $(27,28)$ to assess the efficacy and tolerability of two nasal lavage products available on the market, namely Sterimar ${ }^{\mathrm{TM}}$ (high pressure and low volume) and Sinus Rinse ${ }^{\mathrm{TM}}$ (low pressure and high volume). The solutions were administered by the patient three times a day, once in each nostril, for 12 weeks after surgery, with postoperative assessments conducted in the second, fourth and 12 weeks. There was a reduction in the SNOT-22 score at the first, second and third assessments, with scores of 28,14 and 14 respectively ( $<<0.001)$. A total of 24 ( $2^{\text {nd }}$ week), 22 ( $4^{\text {th }}$ week) and 23 patients $\left(12^{\text {th }}\right.$ week) reported Sinus Rinse ${ }^{\mathrm{TM}}$ as more effective than Sterimar ${ }^{\mathrm{TM}}(\mathrm{p}<0.0001)$, although no difference was observed in patient preference for either of the products $(\mathrm{p}>0.05)$.

Grobler et al. (24) used the endoscopic score to analyze the pre- and postoperative (FESS) size of the ostiomeatal complexes in cases of clinically recalcitrant chronic rhinosinusitis. Nasal irrigation was performed using the following isotonic solution: $200 \mathrm{~mL}$ of water, $5 \mathrm{~mL}$ of dye and a sachet of buffered saline. Patients positioned themselves with their body bent toward the sink and their head hanging down as they performed nasal irrigation. The procedure was carried out once a day, with instillation of $150-200 \mathrm{~mL}$ of solution into the nostrils. Paranasal sinuses that showed the presence of dye had a larger ostiomeatal complex $(7.31 \mathrm{~mm} ; 95 \%$ CI 5.54-9.08) when compared to those in which the dye had not penetrated (1.26mm; 95\% CI 0.86-1.66). Statistical analyses demonstrated that the postoperative sinuses were more prone to penetration of the solution than those not submitted to surgery $(p=0.0016)$. The authors inferred that a critical size of $3.95 \mathrm{~mm}$ was required to obtain $95 \%$ penetration of saline into the ostiomeatal complexes.

\section{Discussion}

The present review found evidence of scientific studies on the topical use of dynamic nasal irrigation in adults suffering from rhinitis, sinusitis and after FESS, and that information on the delivery systems used remains nonhomogeneous.

With respect to the types of delivery systems, the studies analyzed indicated a difference in the nasal irrigation devices chosen. Pynnonen et al. (12) found a significant improvement in rhinosinusitis symptoms with the use of a spray. This result is likely due to the difference in the amount of saline solution used and not how pressure was released, since, according to Harvey et al. (19), large volumes and positive pressure are needed to ensure the mechanical action of saline. It can be inferred that a percentage of the saline particles administered by the spray did not reach the middle meatus, where most of the osteomeatal complex is located. This means the particles could be deposited in the anterior nasal cavum, which seems to have occurred in other studies that use high pressure low volume systems $(5,14,15)$.

Salib et al. (15) also studied different saline delivery methods and inferred that the Sinus Rinse ${ }^{\mathrm{TM}}$ solution was more effective at removing crusts and preventing the formation of adhesions. Although Sterimar ${ }^{\mathrm{TM}}$ uses the same mechanism of action as Sinus Rinse ${ }^{\mathrm{TM}}$, the pressurized saline spray is released in particles, and in this particular study the volume was lower when compared to the amount of liquid released by the squeeze bottle. Due to the inertial impaction phenomenon, it can be inferred that a significant portion of the particles (29) were deposited in the region of the nasal mucosa where flow is turbulent (30), possibly the anterior nasal cavum $(30,31)$, whereas the liquid saline likely reached the nasal conchae, where the middle meatus is located. This result corroborates the concept proposed by 
Harvey et al. (19), whereby large volumes of saline under positive pressure are needed for mechanical clearance to occur. According to the authors, liquid saline instillation under high pressure generates the shear force needed to alter gas-liquid interaction, which favors the removal of viscous mucus adhered to the walls of the airways, inflammatory cells, pollutants and bacteria $(12,18)$.

With respect to the amount of saline needed to obtain the mechanical clearance attributed to this strategy, between 200 and $250 \mathrm{~mL}$ seems to be ideal when irrigation is used in adults with rhinosinusitis $(19,32)$, supporting treatment already applied by medical professionals and physiotherapists in clinical practice.

In regard to the type of saline used, nasal irrigation with isotonic saline improves the nasal MCC of allergic patients due to changes in the rheological properties of mucous (33) and is better tolerated. Chusakul et al. (23) investigated three types of isotonic saline solutions according to their alkalinity. The authors inferred that the similarity between the $\mathrm{pH}$ of the moderately alkaline solution and the physiological $\mathrm{pH}$ of cellular cytoplasm makes its use more soothing to the nasal mucosa cells, thus reducing nasal symptoms. It is important to note that, although there was no difference in MCC, nasal patency or resistance, the quality of life of the patients studied improved. The fact that isotonic saline does not provoke any adverse effects (34) may explain this situation. The feeling of nasal discomfort caused by hypertonic saline (5) can generate sequelae such as obstruction, rhinorrhea and increased glandular secretion, affecting nasal patency (6). Boatsman et al. (35) reported that, despite the importance of MCC in maintaining nasal health and function, its association with rhinosinusitis symptoms was not demonstrated in the population studied.

Unlike the abovementioned results, Ural et al. (18) showed that nasal irrigation with isotonic saline improved the nasal MCC of allergic patients. However, Kim et al. (36) studied the effects of irrigation with three different saline concentrations on cell morphology and mucin secretion in human nasal epithelial cell cultures and found that the group submitted to isotonic saline irrigation exhibited a normal epithelium covered in healthy cilia and preserved cellular integrity, thus favoring MCC. This result differed from those observed in groups that underwent hypertonic saline nasal irrigation, which showed damaged to the epithelium, loss of cellular integrity and the production of mucous. Additionally, isotonic saline did not affect mucin production.

Hauptman et al. (6) investigated the impact of nasal irrigation with two types of saline solution (isotonic and hypertonic) in patients with rhinosinusitis and observed a significant improvement in MCC in both groups studied. However, instillation with hypertonic saline exhibited a greater decline in STT. It is interesting to note that despite the low volume of saline instilled ( $1 \mathrm{~mL}$ of each solution), MCC improved in both groups. This is because hypertonic saline reduces swelling in the nasal mucosa (37) regardless of the amount instilled, with repercussion on MCC. It can be inferred that isotonic saline increased the minimum cross-sectional area 22 to $54 \mathrm{~mm}$ from the nostril (MCA2) and reduced MCC as a result of inertial impaction (29). In other words, particles were deposited in the nasal cavity, likely in the region of the anterior nasal cavum, thereby moistening the mucosa and improving MCC, with greater displacement of secretions and improved patency in the region due to the larger cross-sectional area. Furthermore, although the difference in viscosity between hypertonic and isotonic saline was small, it may have interfered in particle deposition in the nasal mucosa, given the reduced size of the cross-section of the area studied by Hauptman et al. (6). Greater viscosity hampers flow, even when the solution is released under positive pressure, as occurred in the present study. It is likely that the number of particles deposited in the nasal cavity was unable to reduce edema to the point of restoring nasal patency, with an increase in the cross-sectional area; however, the magnitude of its effect improved MCC. In fact, there are reports in the literature (38) of a decline in the area of the nasal cross-section of healthy individuals after instillation of hypertonic saline, due to congestion. This may be the result of the discomfort caused, which leads to nasal obstruction, rhinorrhea and increased glandular secretion.

Low et al. (5) also studied the effect of nasal irrigation with different saline solutions in individuals submitted to FESS and found a 50\% reduction or even complete remission of nasal crusts at the last assessment of the three groups treated, with no difference between the treatments for the duration of the study. A possible explanation for these findings is that saline applied under positive pressure removed the crusts, in addition to reducing edema and 
inflammation of the mucosa (39). Only this study (5) analyzed STT in FESS, obtaining mean baseline STT values higher than the reference values for healthy adults in all three groups assessed $(40,41)$. No difference was observed for this variable in the postoperative phase, despite the removal of nasal crusts.

Analysis of the studies using the PEDro scale (22) showed heterogeneous methodological quality, which may make it difficult to choose the best conduct to be applied by professionals in clinical practice. Moreover, the absence of a control group in all the studies allows us to conclude that the positive results obtained were exclusively due to nasal irrigation. It is also important to underscore that the association of medication and saline irrigation $(5,12,14,20)$ makes it impossible to attribute the findings solely to this non-pharmacological treatment.

\section{Conclusion}

Few studies were identified that elucidate the positive effects of saline irrigation use in adults with rhinitis, sinusitis and submitted to FESS. The evidence found demonstrates that high pressure instillation of large volumes of saline seems to be the most widely used method, considering its mechanical and physiological effects. The ideal amount of saline needed to obtain these effects seems to be between 200 and $250 \mathrm{~mL}$. In regard to the type of solution used, in addition to being better tolerated by patients, isotonic saline nasal irrigation improved nasal MCC in allergic individuals. However, given the relevance of this simple, well-tolerated and minimally invasive technique, further research is needed to better define protocols on the use of nasal irrigation, in order to systematize the process.

\section{References}

1. Bramley TJ, Lerner D, Sames M. Productivity losses related to the common cold. J Occup Environ Med. 2002;44(9):822-9.

2. National Institute for Health and Clinical Excellence. Respiratory tract infections - antibiotic prescribing. Prescribing of antibiotics for self-limiting respiratory tract infections in adults and children in primary care. NICE clinical guideline 69. 2008. p. 1-119.
3. Simasek M, Blandino DA. Treatment of the common cold. Am Fam Physician. 2007;75(4):515-20.

4. Diretrizes Brasileiras de Rinossinusites. Rev Bras Otorrinolaringol. 2008;74(2 Suppl):6-59.

5. Low TH, Woods CM, Ullah S, Carney AS. A double-blind randomized controlled trial of normal saline, lactated Ringer's, and hypertonic saline nasal irrigation solution after endoscopic sinus surgery. Am J Rhinol Allergy. 2014;28(3):225-31.

6. Hauptman G, Ryan MW. The effect of saline solutions on nasal patency and mucociliary clearance in rhinosinusitis patients. Otolaryngol Head Neck Surg. 2007;137(5):815-21.

7. Storms WW. Pharmacologic approaches to daytime and nighttime symptoms of allergic rhinitis. J Allergy Clin Immunol. 2004;114(5 Suppl):S146-53.

8. Tomooka LT, Murphy C, Davidson TM. Clinical study and literature review of nasal irrigation. Laryngoscope. 2000;110(7):1189-93.

9. Georgitis JW. Nasal hyperthermia and simple irrigation for perennial rhinitis. Changes in inflammatory mediators. Chest. 1994;106(5):1487-92.

10. Tano L, Tano K. A daily nasal spray with saline prevents symptoms of rhinitis. Acta Otolaryngol. 2004;124(9):1059-62.

11. Passali D, Damiani V, Passali FM, Passali GC, Bellussi L. Atomized nasal douche vs nasal lavage in acute viral rhinitis. Arch Otolaryngol Head Neck Surg. 2005;131(9):788-90.

12. Pynnonen MA, Mukerji SS, Kim HM, Adams ME, Terrell JE. Nasal saline for chronic sinonasal symptoms: a randomized controlled trial. Arch Otolaryngol Head Neck Surg. 2007;133(11):1115-20.

13. Rabago D, Barrett B, Marchand L, Maberry R, Mundt M. Qualitative aspects of nasal irrigation use by patients with chronic sinus disease in a multimethod study. Ann Fam Med. 2006;4(4):295-301.

14. Freeman SR, Sivayoham ES, Jepson K, Carpentier J. A preliminary randomised controlled trial evaluating the efficacy of saline douching following endoscopic sinus surgery. Clin Otolaryngol. 2008;33(5):462-5 
15. Salib RJ, Talpallikar S, Uppal S, Nair SB. A prospective randomised single-blinded clinical trial comparing the efficacy and tolerability of the nasal douching products Sterimar and Sinus Rinse following functional endoscopic sinus surgery. Clin Otolaryngol. 2013;38(4):297-305.

16. Achilles N, Mosges R. Nasal saline irrigations for the symptoms of acute and chronic rhinosinusitis. Curr Allergy Asthma Rep. 2013;13(2):229-35.

17. Olson DE, Rasgon BM, Hilsinger Jr RL. Radiographic comparison of three methods for nasal saline irrigation. Laryngoscope. 2002;112(8 Pt 1):1394-8.

18. Ural A, Oktemer TK, Kizil Y, Ileri F, Uslu S. Impact of isotonic and hypertonic saline solutions on mucociliary activity in various nasal pathologies: clinical study. J Laryngol Otol. 2009;123(5):517-21.

19. Harvey R, Hannan SA, Badia L, Scadding G. Nasal saline irrigations for the symptoms of chronic rhinosinusitis. Cochrane Database Syst Rev. 2007;(3):CD006394.

20. Nguyen SA, Psaltis AJ, Schlosser RJ. Isotonic saline nasal irrigation is an effective adjunctive therapy to intranasal corticosteroid spray in allergic rhinitis. Am J Rhinol Allergy. 2014;28(4):308-11.

21. Albu S. Novel drug-delivery systems for patients with chronic rhinosinusitis. Drug Des Devel Ther. 2012;6:125-32.

22. The physiotherapy evidence database (PEDro). [cited 2016 Jan 22]. Available from: https://tinyurl.com/ k6m8ky2.

23. Chusakul S, Warathanasin S, Suksangpanya N, Phannaso C, Ruxrungtham S, Snidvongs K, et al. Comparison of buffered and nonbuffered nasal saline irrigations in treating allergic rhinitis. Laryngoscope. 2013;123(1):53-6.

24. Grobler A, Weitzel EK, Buele A, Jardeleza C, Cheong YC, Field J, et al. Pre- and postoperative sinus penetration of nasal irrigation. Laryngoscope. 2008;118(11):2078-81.

25. Piccirillo JF, Merritt Jr MG, Richards ML. Psychometric and clinimetric validity of the 20-Item Sino-Nasal Outcome Test (SNOT-20). Otolaryngol Head Neck Surg. 2002;126(1):41-7.
26. Bezerra TFP, Piccirillo JF, Fornazieri MA, Pilan RRM, Abdo TRT, Pinna FR, et al. Cross-Cultural Adaptation and Validation of SNOT-20 in Portuguese. Int J Otolaryngol. 2011;2011:ID306529.

27. Hopkins C1, Gillett S, Slack R, Lund VJ, Browne JP. Psychometric validity of the 22-item Sinonasal Outcome Test. Clin Otolaryngol. 2009;34(5):447-54.

28. Caminha GP, Melo Jr JT, Hopkins C, Pizzichini E, Pizzichini MM. SNOT-22: psychometric properties and cross-cultural adaptation into the Portuguese language spoken in Brazil. Braz J Otorhinolaryngol. 2012;78(6):34-9.

29. Raul JL. Humidity and Aerosol Therapy. In: Barnes TA, editor. Core Textbook of Respiratory Care Practice. Chicago: Mosby; 1993. p. 179-97.

30. Mlynski G, Grützenmacher S, Plontke S, Mlynski $B$, Lang C. Correlation of nasal morphology and respiratory function. Rhinology. 2001;39(4):197-201.

31. Grützenmacher S, Robinson DM, Sevecke J, Mlynski G, Beule AG. Comparative investigations of anatomy and physiology in mammalian noses (Homo sapiens-Artiodactyla). Rhinology. 2011;49(1):18-23.

32. Jorissen M. Postoperative care following endoscopic sinus surgery. Rhinology. 2004;42(3):114-20.

33. Liang J, Lane AP. Topical Drug Delivery for Chronic Rhinosinusitis. Curr Otorhinolaryngol Rep. 2013;1(1):51-60.

34. Hermelingmeier KE, Weber RK, Hellmich M, Heubach $\mathrm{CP}$, Mösges R. Nasal irrigation as an adjunctive treatment in allergic rhinitis: a systematic review and meta-analysis. Am J Rhinol Allergy. 2012;26(5):e119-25.

35. Boatsman JE, Calhoun KH, Ryan MW. Relationship between rhinosinusitis symptoms and mucociliary clearance time. Otolaryngol Head Neck Surg. 2006;134(3):491-3.

36. Kim CH, Hyun Song M, Eun Ahn Y, Lee JG, Yoon JH. Effect of hypo-, iso- and hypertonic saline irrigation on secretory mucins and morphology of cultured human nasal epithelial cells. Acta Otolaryngol. 2005;125(12):1296-300.

37. Talbot AR, Herr TM, Parsons DS. Mucociliary clearance and buffered hypertonic saline solution. Laryngoscope. 1997;107(4):500-3. 
38. Baraniuk JN, Ali M, Yuta A, Fang SY, Naranch K. Hypertonic saline nasal provocation stimulates nociceptive nerves, substance $P$ release, and glandular mucous exocytosis in normal humans. Am J Respir Crit Care Med. 1999;160(2):655-62.

39. Huang AG, Govindaraj S. Topical therapy in the management of chronic rhinosinusitis. Curr Opin Otolaryngol Head Neck Surg. 2013;21(1):31-8.

40. Puchelle E, Aug F, Pham QT, Bertrand A. Comparison of three methods for measuring nasal mucociliary clearance in man. Acta Otolaryngol. 1981;91(3-4):297-303
41. Goto DM, Lanca M, Obuti CA, Barbosa CMG, Saldiva PHN, Zanetta DMT, et al. Effects of biomass burning on nasal mucociliary clearance and mucus properties after sugarcane harvesting. Environ Res. 2011;111(5):664-9.

Received in 12/09/2015

Recebido em 09/12/2015

Approved in 03/02/2017

Aprovado em 02/03/2017 